\title{
CORRECTION
}

View Article Online

View Journal I View Issue

D) Check for updates

Cite this: RSC Chem. Biol., 2021, 2, 1297

DOI: $10.1039 / \mathrm{d} 1 \mathrm{cb} 90021 \mathrm{~h}$

rsc.li/rsc-chembio

\section{Correction: Antibody recruiting molecules (ARMs): synthetic immunotherapeutics to fight cancer}

\author{
Silvia Achilli, Nathalie Berthet* and Olivier Renaudet*
}

Correction for 'Antibody recruiting molecules (ARMs): synthetic immunotherapeutics to fight cancer' by Silvia Achilli et al., RSC Chem. Biol., 2021, 2, 713-724. DOI: 10.1039/d1cb00007a.

The authors regret mistakes in the structures depicted in Table 1, entry A and Table 2, entry B. The correct version of both tables are shown below. The conclusions of the paper have not been affected. 


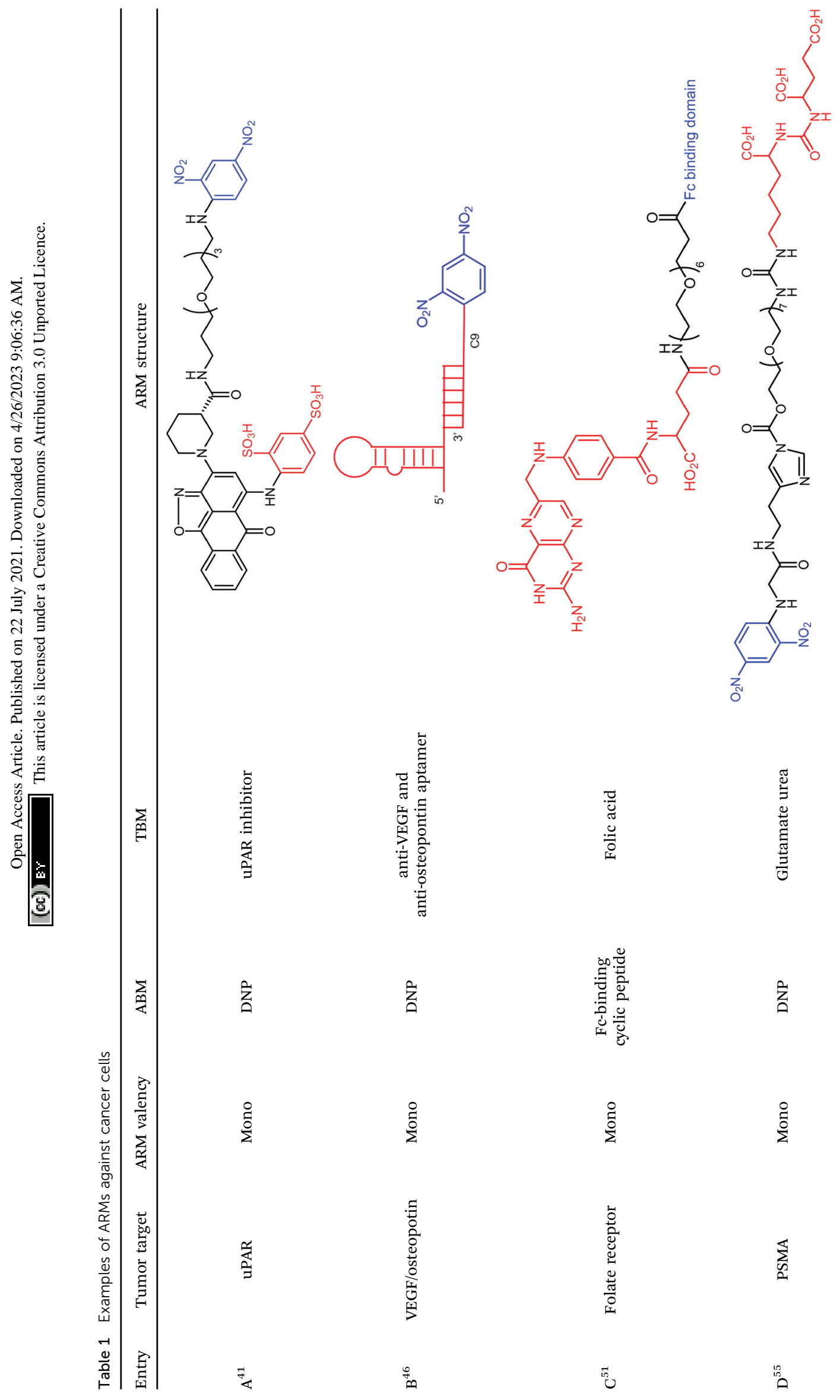




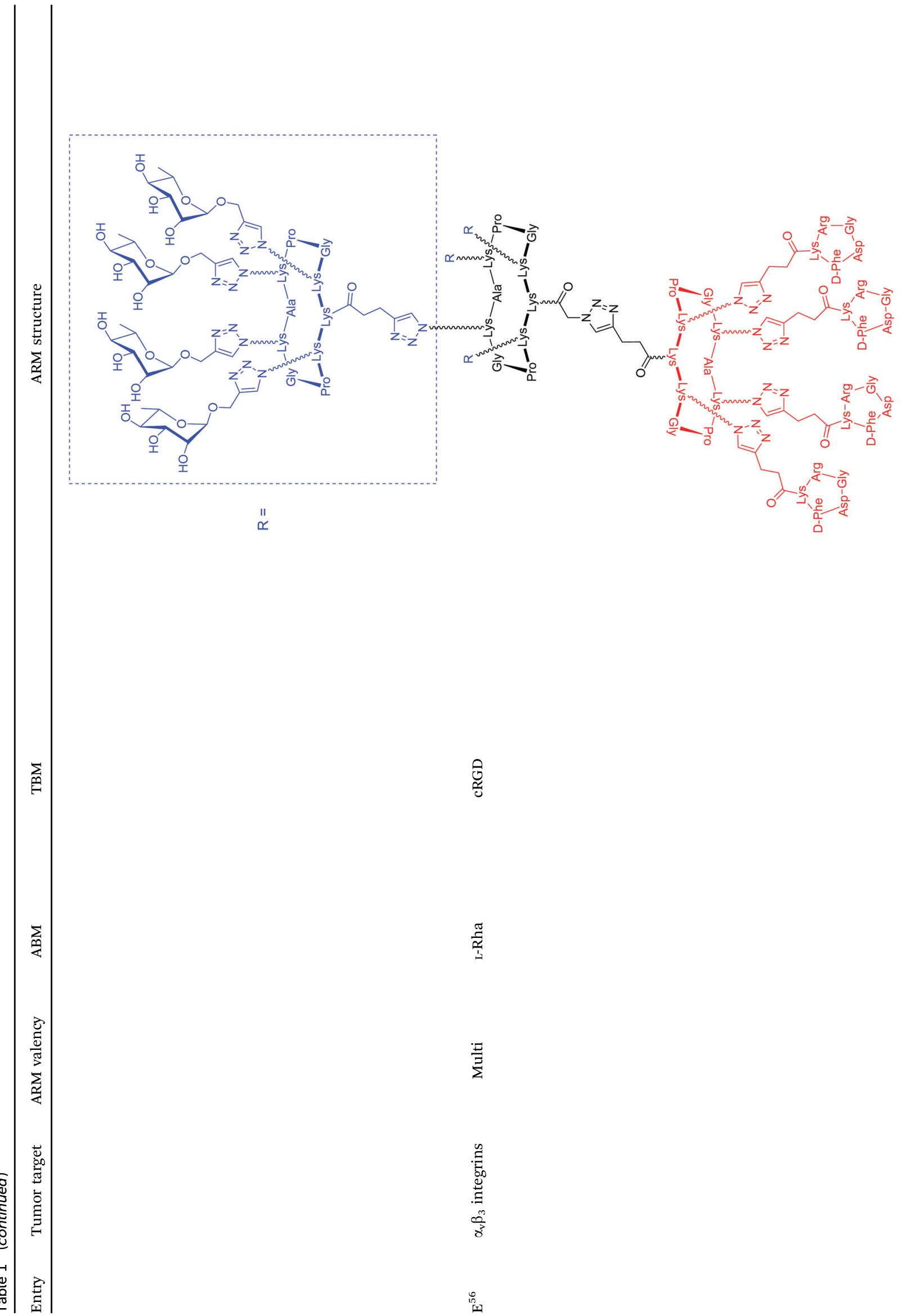


Table 2 Example of ARMs using unspecific targeting of the cancer cell membrane with lipid anchor

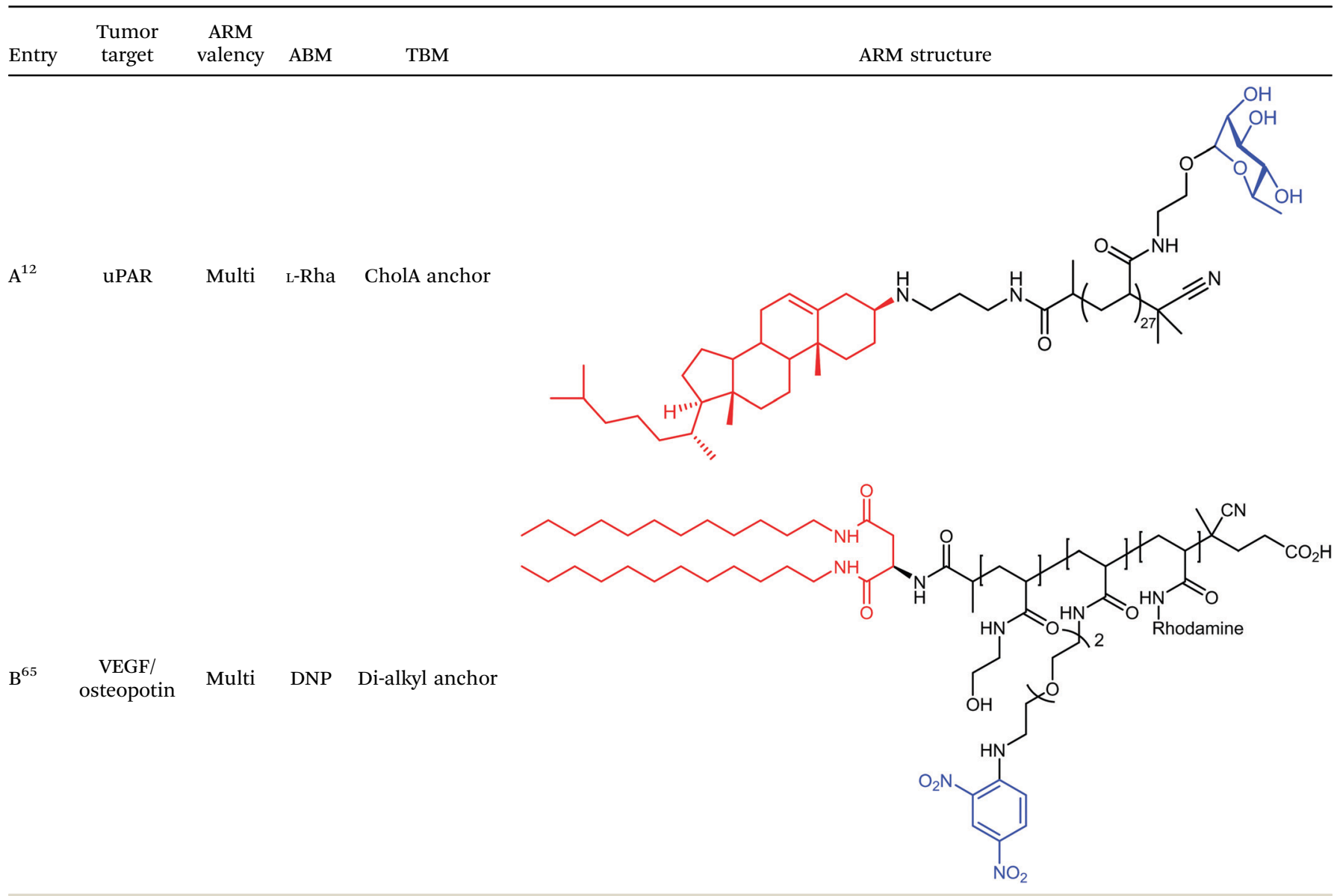

The Royal Society of Chemistry apologises for these errors and any consequent inconvenience to authors and readers. 